\title{
DETERMINATION OF THE AVERAGE MAINTENANCE TIME OF CNC MACHINE TOOLS BASED ON TYPE II FAILURE CORRELATION
}

\section{OKREŚLENIE ŚREDNIEGO CZASU KONSERWACJI OBRABIAREK CNC W OPARCIU O KORELACJĘ AWARII TYPU II}

\begin{abstract}
An average maintenance time calculation method based on components failure correlation analysis is proposed to revise the traditional system maintenance time. This paper focus on complex system type II fault correlation, using the Decision-making trial and evaluation laboratory / Interpretative structural model method to divide the fault level of components. And the copula connection function is introduced to calculation of failure rate function of failure correlation components. In addition, the system maintenance time model is established by synthesizing the failure rate function of each unit of the system. Moreover, the average maintenance time under the minimum number of failures is determined. This method shows that the minimum average maintenance time of the proposed system is more reasonable than the traditional one and provides the basis for system and component reliability design.
\end{abstract}

Keywords: CNC machine tools, Average maintenance time, Type II failure correlation, DEMATEL/ISM, Copula function.

\begin{abstract}
W artykule zaproponowano metodę obliczania średniego czasu konserwacji, oparta na analizie korelacji uszkodzeń elementów skladowych systemu. Metoda ta ma na celu rewizję tradycyjnego czasu konserwacji systemu. Głównym tematem pracy jest korelacja awarii typu II wystepujących w systemach złożonych. Elementy systemu podzielono ze względu na poziom uszkodzenia przy użyciu metody DEMATEL w połaczeniu z interpretacyjnym modelowaniem strukturalnym. Funkcję intensywności skorelowanych uszkodzeń elementów systemu obliczono za pomoca funkcji łaczącej (kopuły). Dodatkowo, opracowano model czasu konserwacji systemu poprzez synteze funkcji intensywności uszkodzeń każdej jednostki systemu. Ponadto, określono średni czas konserwacji dla minimalnej liczby uszkodzeń. Metoda ta pokazuje, że minimalny średni czas konserwacji proponowanego systemu jest korzystniejszy niz tradycyjnie przyjęty i stanowi podstawę do projektowania niezawodności systemu i jego składowych.
\end{abstract}

Stowa kluczowe: obrabiarki CNC, średni czas konserwacji, korelacja awarii typu II, DEMATE /ISM, funkcja kopula.

\section{Introduction}

Maintenance is an important attribute of product quality. It refers to the prescribed procedures and methods that a product undergoes under specified conditions and time to maintain or restore its regular state [5, 24]. A maintenance program analyzes, predicts, and evaluates the quality of the product and establishes a variety of physical and mathematical models. The program is essential and strongly influences the product maintenance level $[1,14,17]$.

Research on maintenance models is divided into qualitative description and quantitative analysis. Qualitative description includes a descriptive model, flow chart, and graphic model. Literature shows that research on the quantitative analysis of repair time is relatively weak $[4,7,13,18,19]$. More research has focused on the replacement time and, average repair time for model assumptions, parameters estimation, and hypothesis testing. [3] showed that the maintenance time of $\mathrm{CNC}$ machine tools could be statistically analyzed. Assuming that the system maintenance time possesses a lognormal distribution, the maximum likelihood method can be used to estimate the parameters, and the skewness--kurtosis test can be conducted to obtain the maintenance time distribution. In [25], we use the Origin 8 drawing function to plot the probability density function graph of an $\mathrm{NC}$ ma- chining center and judge its possible distribution rule. Then, we use a MATLAB programming function to estimate the parameters and obtain the maintenance time model. In [3] and [25], the maintenance time of all components was indiscriminately based on experience, and the system maintenance time was assumed to follow a certain distribution model. The distribution model was determined by model hypothesis, parameter estimation, and hypothesis testing. Finally, the average maintenance time of the system is determined by point estimation. Most modern mechanical systems comprise the key system units. System failure must be closely related with the system unit; thus, the maintenance time modeling process should consider the role of the system unit.

In [22], a maintenance operation comprised multiple maintenance tasks. Maintenance operation was divided into serial maintenance operations, parallel repair operations, and serial parallel maintenance operations according to the relationship between the maintenance operations; in turn, the maintenance time calculation model was given. In [8], the system maintenance time comprised different maintenance times. Therefore, the subsystem maintenance activity indivisible was defined as the basic maintenance event. The system maintenance work sequence is divided into serial, parallel and hybrid, and the final formula was based on the whole probability of the system to obtain 
the average maintenance time. In [9], three kinds of logical relations existed between the system maintenance operations: serial, parallel, and selection. These logical relations then built the maintenance process model based on Colored Stochastic Petri Net (CSTPN). The model was used to propose a maintenance time simulation algorithm using the Monte Carlo method. the maintenance time of the subsystem is considered in [8], [9], and [22], and the corresponding system maintenance time model was established according to the different logical relations among the subsystems. However, a huge error was encountered in the system average maintenance time due to the failure in the correlation between the subsystems. This phenomenon resulted in the failure of, the maintenance cycle plan to satisfy actual project requirements, thereby affecting maintenance efficiency.

System maintenance time function is constituting by the component failure rate and maintenance time. Therefore, this paper studies the type II fault correlation $[11,26]$, which is when a component in the system fails, it will affect the failure rate of other components. And aiming at the serial system, establishing the component failure correlation model by considering the failure rate of the system components. In addition, the average maintenance time model with the minimum failure rate of the system is obtained by weighting the subsystem failure rate. Taking CNC machine tools as an example, the concrete modeling process is introduced to provide a theoretical basis for the system maintenance time design and maintenance plan formulation.

\section{Modeling principle of system average maintenance time based on fault correlation}

\subsection{Implementation of component-level division based DEMATEL / ISM method}

Decision-making trial and evaluation laboratory (DEMATEL) is a systematic method of analysis using graph theory and matrix tools. The method studies the complex relationship between the systems converted to visualize the structure of the model, and thus the complex system dependencies between the elements, to make a quantitative analysis, and clarify the key factors [21].

Interpretive structural modeling (ISM) system is used for the analysis of complex issues related to the socio-economic system and development. The idea of this method is to divide the complex system into several sub-systems, draw the relation graph, reflect the direct relationship between the system elements using adjacency matrix, and then transform the adjacency matrix into a reachable matrix. The reachable matrix decomposition is then transformed into a complex system that constitutes a clear multi-level hierarchical structure model [10]; thus, a professional explanation and interpretation of the completion of the structural model are achieved.

This article uses the integrated DEMATEL / ISM method combined with machine fault correlation analysis to clarify the relationship between the system elements and to simplify ISM modeling of large and complex matrix operations. First, a subsystem failure correlation network is established based on the subsystem failure correlation data. Second, the DEMATEL is used to calculate calculated the comprehensive influence matrix of the system to obtain the correlation order of the fault subsystem and discover the key subsystems. Moreover, the overall influence matrix of the system (is unit matrix) is determined, then the reachability matrix $\mathbf{M}$ is obtained. Finally, the ISM method of grading system and domain decomposition is used to analyze the complex issues of hierarchical relationships between the subsystems. The integration of the two methods clarifies the ef- fect of the failure of the subsystem as well as the mechanism of fault transmission.

The procedure in determining the reachability matrix using the DEMATEL method is presented as follows:

1) Determine the correlation matrix, represents the number of impact of influencing factors and; $i=j$, gives $y_{i j}=0$.

2) Normalized correlation matrix to obtain Normalized matrix $\mathbf{X}$ :

$$
\mathbf{X}=\frac{\mathbf{Y}}{\max _{l<i<n} \sum_{j=1}^{n} y_{i j}}
$$

3) Determine the comprehensive influence matrix $\mathbf{T}$ :

$$
\begin{gathered}
\mathbf{T}=\lim _{k \rightarrow \infty}\left(\mathbf{X}+\mathbf{X}^{2}+\cdots+\mathbf{X}^{k}\right)=\mathbf{X}(\mathbf{I}-\mathbf{X})^{-1} \\
\mathbf{T}=\left[t_{i j}\right]_{n \times n}, i, j=1,2, \cdots, n
\end{gathered}
$$

I is the identity matrix, and $t_{i j}$ is the integrated effect of component $i$ and component $j$, including direct and indirect effect.

4) Determine the overall system impact matrix $\mathbf{H}$ :

$$
\mathbf{H}=\mathbf{T}+\mathbf{I}
$$

Then the reachability matrix $\mathbf{M}$ is obtained by the overall system impact matrix $\mathbf{H}$.

Finally, the failure to obtain the hierarchical relationships between

$\longrightarrow$ Intermediate subsystem $\longrightarrow$ Representation subsystem

Fig. 1. Hierarchy relationship of system component

the subsystems using the ISM method classification system and domain decomposition is shown in Figure 1.

\subsection{Reliability modeling of system components based on Copula function}

First, the reliability of each system component is modeled based on time correlation. Then consider the fault correlation and the transmission of the hierarchy subsystem shown in Figure 1. Moreover, the joint distribution function is established using the copula connection function to determine the fault correlation coefficients among system components, thereby establishing a system reliability model based on fault related components.

\subsubsection{Time-dependent system component reliability modeling}

A two-parameter Weibull distribution [12] for reliability modeling is introduced in this paper. After the establishment of a system component failures time model, considering the small sample size of each system component, the maximum likelihood estimation method (MLE) is used to estimate the parameters to improve the accuracy of parameter estimation.

$t_{1}, t_{2}, \cdots, t_{n}$ are set up for fault interval time order statistics, using MLE. The shape parameter $\hat{\beta}$ and scale parameter $\hat{\alpha}$ can satisfy the following equation: 


$$
\hat{\alpha}=\left(\frac{1}{n} \sum_{i=1}^{n} t_{i}^{\hat{\beta}}\right)^{1 \hat{\beta}} \frac{1}{\hat{\beta}}=\frac{\sum_{i=1}^{n} t_{i}^{\hat{\beta}} \ln t_{i}}{\sum_{i=1}^{n} t_{i}^{\hat{\beta}}}-\frac{1}{n} \sum_{i=1}^{n} \ln t_{i}
$$

$\hat{\beta}_{k}-\hat{\beta}$ is obtained after $k$ times iterations;

As the iteration number increases, its value approaches the optimal solution. The iterative algorithm is shown as follows:

$$
\begin{aligned}
& \left\{\begin{array}{c}
\hat{\beta}_{k+1}=\frac{1}{2} \hat{\beta}_{k}+\frac{1}{2}\left[h\left(\hat{\beta}_{k}\right)-\bar{X}\right]^{-1} \\
\hat{\beta}_{0}=1.0
\end{array}\right. \\
& \bar{X}=\frac{1}{n} \sum_{i=1}^{n} t_{i}^{\hat{\beta}_{k}} ; h\left(\hat{\beta}_{k}\right)=\frac{\sum_{i=1}^{n} t_{i}^{\hat{\beta}} \ln t_{i}}{\sum_{i=1}^{n} t_{i}^{\hat{\beta}}}
\end{aligned}
$$

The decreased number of system component fault data results in a small sample problem. Result obtained using the MLE have certain deviations, thereby requiring parameter estimation based on the results of a deviation correction.

$$
\beta^{*}=\gamma_{\beta}(n) \hat{\beta}
$$

$\gamma_{\beta}(n)$ is known as $\hat{\beta}$ of the correction coefficient and calculated by the following formula:

When $n$ is an even number and $n \geq 4$ :

$$
\gamma_{\beta}(n)=\sqrt{\frac{\pi}{n}} \times \frac{1 \times 3 \times \cdots \times(\mathrm{n}-3)}{2^{\frac{\mathrm{n}-3}{2}\left(\frac{\mathrm{n}}{2}-2\right) !}}
$$

When $n$ is an odd number and $\mathrm{n} \geq 5$ :

$$
\gamma_{\beta}(n)=\frac{2^{\frac{n}{2}-1}}{\sqrt{n \pi}} \times \frac{\left(\frac{\mathrm{n}-3}{2}\right) !}{1 \times 3 \times \cdots \times(\mathrm{n}-4)}
$$

For any $n \geq 3, \gamma_{\beta}(n)<1$ and $\lim _{n \rightarrow \infty} \gamma_{\beta}(n)=1$; thus, $\beta^{*}<\hat{\beta}$, and using formula (9) to correct the deviation of shape parameter $\beta$.

The deviation correction formula of scale parameter $\alpha$ is:

$$
\begin{gathered}
\alpha^{*}=\gamma_{\alpha}\left(n, \beta^{*}\right) \hat{\alpha} \\
\gamma_{\alpha}\left(n, \beta^{*}\right)=\frac{n^{\frac{1}{\beta^{*}}}(n-1) !}{\Gamma\left(n+\frac{1}{\beta^{*}}\right)}
\end{gathered}
$$

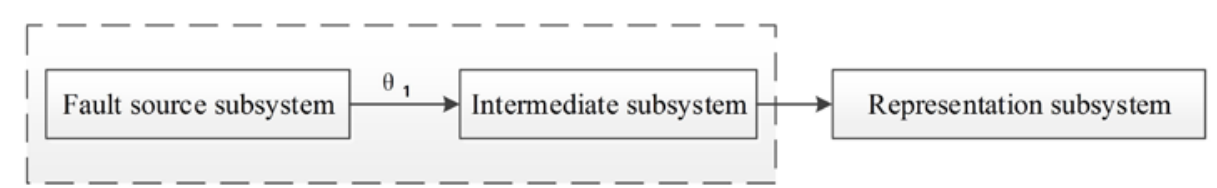

After the parameters are estimated, the $d$ test method is used to test the system component failure of the time interval distribution function and goodness-of-fit test.

\subsubsection{Reliability model based on failure rate correlation subsys- tem}

(1) Fault correlation coefficient modeling of system components based on copula function

Considering the failure time correlation of system components to establish the time-dependent reliability model. Then the fault correlation and transfer of the system components are considered, and the copula connection function is used to calculate the failure correlation coefficient.

The copula theory was proposed by Sklar in 1959. This theory can decompose a joint distribution function into a Copula function and $k$ marginal distribution $[15,27]$. In addition, this theory follows the Sklar theorem:

$H(\cdot, \cdot)$ is a joint distribution function of $F(\cdot)$ and $G(\cdot)$. A function of copula $C(\cdot, \cdot)$ satisfies $H(x, y)=C(F(x), G(y))$. If $F(\cdot)$ and $G(\cdot)$ are continuous, then $C(\cdot, \cdot)$ is the only; otherwise, if $F(\cdot)$ and $G(\cdot)$ are a univariate distribution function and $C(\cdot, \cdot)$ is a corresponding copula function, then the function $H(\cdot, \cdot)$ is the joint distribution function with marginal distribution $F(\cdot)$ and $G(\cdot)$.

Based on experience, the system component time between failure obeys Weibull distribution is generally uses the Gumbel-copula function and is expressed as follows:

$$
C\left(R_{1}(t), R_{2}(t), \ldots, R_{n}(t)\right)=\exp \left\{-\left[\sum_{i=1}^{n}\left(-\ln R_{i}(t)\right)^{1 / \theta}\right]^{\theta}\right\}, \theta \in(0,1]
$$

$R_{i}(t)$ is component time-dependent reliability model, $\mathrm{i}=1,2, \ldots, \mathrm{n}$

And $\theta$ is a random variable, where $\theta=1$, if $n$ system components are independent of each other; on the contrary, $\theta$ is closer to 0 , if $n$ system components have a stronger reliability correlation. Thus, the random variable $\theta$ is also known as the correlation coefficient. As a result, how to calculate $\theta$ is the key to the establishment of system model.

Based on the relationship between the system components, the correlation between the system components can be established, and the correlation coefficient $\theta$ shown as follow:

Figure 2 shows that the system can be divided into three levels with an associated system component failure. And the components of the fault source subsystem and intermediate fault subsystem as well as their reliability marginal distribution function. In addition, the copula connection function is introduced and the joint distribution function is established to determine the fault correlation coefficients among system components, thereby establishing the system reliability model based on failure rate correlation components.

In the system with $k$ failure rate correlation components, suppose the reliability function of each system component, $R_{i}\left(t_{i}\right)$, $\mathrm{i}=1,2, \ldots, \mathrm{k} ;$ a copula function $C\left(R_{1}\left(t_{1}\right), R_{2}\left(t_{2}\right), \ldots, R_{k}\left(t_{k}\right)\right)$, such

Fig. 2. Fault source subsystem and intermediate subsystem failure associated schematic 
that $R\left(t_{1}, t_{2}, \ldots, t_{k}\right)=C\left(R_{1}\left(t_{1}\right), R_{2}\left(t_{2}\right), \ldots, R_{k}\left(t_{k}\right)\right)$, can be uniquely identified. Among the $R\left(t_{1}, t_{2}, \ldots, t_{k}\right)$ is the $R_{i}\left(t_{i}\right)$ of the reliability joint distribution function of $k$ failure rate correlation components.

Each system component in the event of failure needs to be shut down for maintenance, then system can be regarded as a series system. The system components of the fault are both independent and non-independent; thus, the system reliability function is solved as:

$$
\begin{gathered}
R(t)=\prod_{i=1}^{n_{1}} C_{i}(t) \prod_{j=1}^{n_{2}} R_{j}(t) \\
n=n_{1}+n_{2}
\end{gathered}
$$

Where:

$$
\begin{aligned}
& n \text { is the number of system components; } \\
& n_{1} \text { is the number of components with fault correlation; } \\
& n_{2} \text { is the number of components with fault independent; } \\
& C_{i}(t) \text { is the integrated reliability of the component } i ; \\
& R_{j}(t) \text { is the reliability of the component } j .
\end{aligned}
$$

(2) Failure rate modeling of system components based on failure rate correlation

According to [16], when a subsystem $j$ is affected by subsystem $i$, the comprehensive failure rate is:

$$
\begin{gathered}
\lambda_{j}(t)=\phi_{j}\left[\lambda_{I j}(t), \lambda_{i_{j}}(t)_{g}, t\right] \\
=\lambda_{I j}(t)+\sum_{i_{j}} \varphi_{i_{j}} \lambda_{i_{j}}(t)_{g}
\end{gathered}
$$

Where $\lambda_{j}(t)$ is the comprehensive failure rate of component $j$;

$\lambda_{I j}(t)$ is the independent failure rate of component $j$;

$\varphi_{i_{j}}(t)$ is the correlation coefficient of component $i$ on com-

ponent $j$;

$\lambda_{i_{j}}(t)_{g}$ is the correlation failure rate of components $i$ related

to component $j$.

$\lambda_{j}(t)$ is generally obtained from the field failure data; $\lambda_{I j}(t)$ is determined by the inherent reliability, usually through factory testing or production data. If relevant effect is not considered, then theoretically $\lambda_{j}(t)=\lambda_{I j}(t)$. On the contrary, the copula theory is expressed in this article as $\varphi_{i_{j}}(t) \in[0,1]$, where $\varphi=0$, indicates no correlation, and $\varphi=1$ indicates completely relevance. That is, a failure of subsystem $i$ will inevitably induce failure of components $j$; thus, $j$ can be replaced by using $(1-\theta)$.

The integrated failure rate of each subsystem level can be obtained as:

$$
\lambda_{F}(t)=\lambda_{1}(t) \lambda_{I}(t)=\lambda_{2}(t)+\left(1-\theta_{1}\right) \lambda_{1}(t)
$$

Where $\lambda_{F}(t)$ and $\lambda_{I}(t)$ are the failure rate of fault source subsystem and intermediate fault subsystem respective with failure rate correlation; $\lambda_{1}(t)$ and $\lambda_{2}(t)$ are the failure rate of fault source subsystem and intermediate fault subsystem respective with fault independent; $\theta_{1}$ is the correlation coefficient between fault source subsystem and intermediate fault subsystem.
Given that the representation subsystem is affected by the failure of the source subsystem and the intermediate subsystem as a whole, the integrated failure rate must be obtained:

$$
\begin{aligned}
& \lambda_{12}(t)=-\frac{R_{12}^{\prime}(t)}{R_{12}(t)} \\
& \lambda_{R}(t)=\lambda_{3}(t)+\left(1-\theta_{2}\right) \lambda_{12}(t)
\end{aligned}
$$

Where $\lambda_{12}(t)$ is the integrated failure rate of fault source subsystem and intermediate fault subsystem; $R_{12}(t)$ is the integrated reliability function of fault source subsystem and intermediate fault subsystem;

$R_{12}^{\prime}(t)$ is the partial derivative of $R_{12}(t) ; \lambda_{3}(t)$ is the failure rate of representation subsystem with fault independent; $\lambda_{R}(t)$ is the failure rate of representation subsystem with failure rate correlation; $\theta_{2}$ is the correlation coefficient between representation subsystem and the whole of fault source subsystem and intermediate fault subsystem.

\subsection{Maintenance time modeling of system components based on small sample}

In the modeling process of system component maintainability, the small sample features of the system components are considered, using the normal distribution of small sample data processing and the particle swarm optimization algorithm. These procedures are conducted to optimize the parameters estimation, to determine the maintenance time model and calculate the average repair time of the system components, which provide the basis for the maintenance time calculation of the system component failure correlation.

Fault repair time $\tau$ is subject to a lognormal distribution $L N\left(\mu, \sigma^{2}\right)$. Its logarithm $\ln \tau$ satisfies the normal distribution $N\left(\mu, \sigma^{2}\right)$.

The probability density function of repair time $\tau$ is expressed as:

$$
m(\tau)=\frac{1}{\sigma t \sqrt{2 \pi}} \exp \left\{-\frac{1}{2}\left(\frac{\ln \tau-\mu}{\mu}\right)^{2}\right\}
$$

The cumulative distribution function is expressed as:

$$
M(\tau)=\int_{0}^{\tau} \frac{1}{\sigma x \sqrt{2 \pi}} \exp \left\{-\frac{1}{2}\left(\frac{\ln x-\mu}{\sigma}\right)^{2}\right\} d x
$$

Where $\sigma$ and $\mu$ are parameters to be estimated.

Parameters $\sigma$ and $\mu$ are estimated. Samples $\tau_{1}, \tau_{2}, \ldots \tau_{n}$ are set as the maintenance time data for a hierarchical system components. The maintenance probability estimate value $\hat{p}_{i}$ at sample $\tau_{i}$ is expressed as:

$$
\hat{p}_{i}=t_{n-1}\left(\sqrt{\frac{n}{n+1} \cdot \frac{X_{i}-\bar{X}}{S}}\right)
$$

$$
\begin{aligned}
& X_{i}=\ln \tau_{i}, \bar{X}=\frac{1}{n} \sum_{i=1}^{n} \ln \tau_{i} \\
& S=\frac{1}{n-1} \sqrt{\left(X_{i}-\bar{X}\right)^{2}}
\end{aligned}
$$


The repair probability estimate $\hat{p_{i}}$ is obtained through $X_{i}=\ln \tau_{i}$, each of which can be further obtained as $\left(\tau_{i}, \hat{p}_{i}\right)$ point. Moreover, the maintenance level of the subsystem parameters of the model estimates can be obtained when combined with the least squares method.

The constraint criterion of the least squares method is expressed as:

$$
Q=\sum_{i=1}^{n}\left[\int_{0}^{\tau_{i}} \frac{1}{\sigma x \sqrt{2 \pi}} \exp \left\{-\frac{1}{2}\left(\frac{\ln x-\mu}{\tilde{A}}\right)^{2}\right\} d x-\hat{p}_{i}\right]^{2}=\min
$$

In (18), the parameter of constrained least squares method is solved using particle swarm optimization (PSO) $[20,23,6]$ under the guidelines of the optimization problem. The PSO optimization algorithm flow chart is shown in Fig. 3.

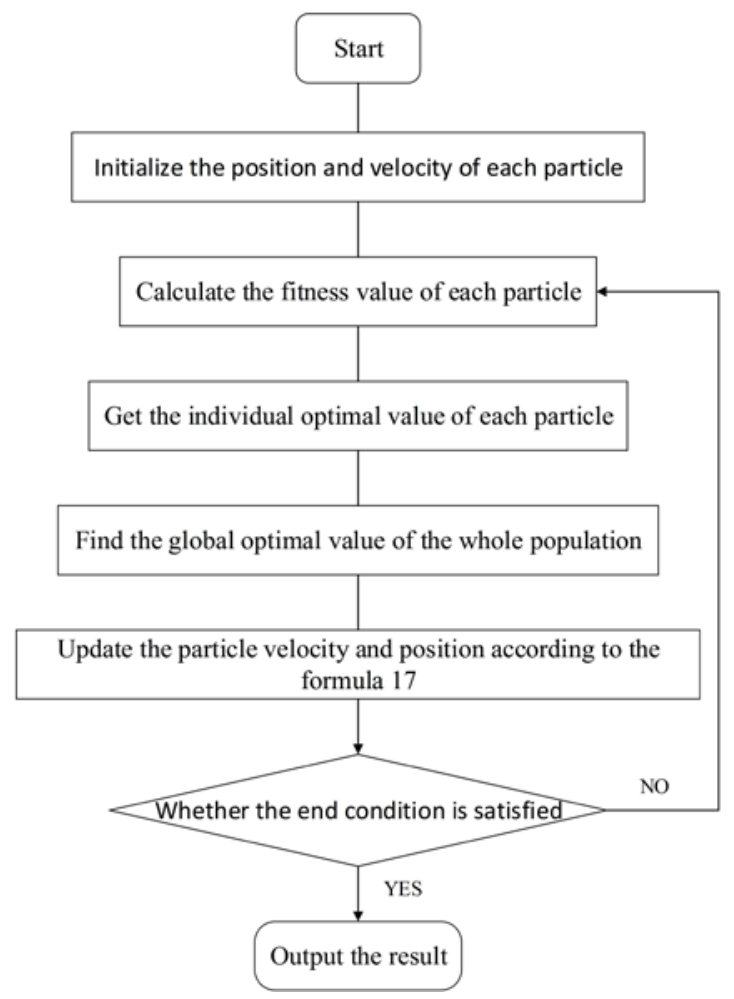

Fig. 3. PSO algorithm flowchart

\subsection{System average maintenance time modeling}

The system maintenance time can be expressed as a function of its components maintenance time; thus, the integrated maintenance time of the system can be obtained by calculating the components average maintenance time. System MTTR (Mean time to repair) can be calculated by system components MTTR, and the weighting factor is related to the number of failures of the system components [2].

$$
M T T R=\frac{\sum_{i=1}^{n} q_{i} f_{i} M_{T T R}}{\sum_{i=1}^{n} q_{i} f_{i}}
$$

Where $M T T R_{i}$ is average maintenance time of component $i, f_{i}$, is the number of faults in the system design life cycle for component $i$, $q_{i}$ is the number of component $i$.
Given that the number of failures of the system components is closely related to the failure rate of all components and the failure dependencies between the system components makes the weighting factor more accurate and reasonable, the use of $\lambda_{i}$ is possible instead of $f_{i}$. In other general system, system components are relatively in unique division; thus, $q_{i}=1$, and the average system maintenance time can be rewritten as:

$$
\text { MTTR }=\frac{\sum_{i=1}^{n} \mathrm{I}_{i}{ }^{M T T R} R_{i}}{\sum_{i=1}^{n} \mathrm{I}_{i}}
$$

Where $\lambda_{i}$ is failure rate for system components in all levels.

The model comprehensively considers the failure time correlation and fault transfer of each component, that is, the corresponding weight maintenance coefficient is given to different system components for repair time calculation and engineering practice.

\section{Application example}

In this paper, modular methods for the whole function of subsystems are used in combination with the main structure and working process of CNC machine tools, as shown in Table 1.

Table 1 shows five CNC machine tools tracked by the task group from July 1, 2012 to December 31, 2012 in time-truncated mode. The cumulative working time was 2,668 hours (two shifts). The collection and analysis of $\mathrm{CNC}$ machine tools used to collate the failure data are shown in Table 2.

The above associated failure statistics is presented as a fault directed graph in Fig. 4.

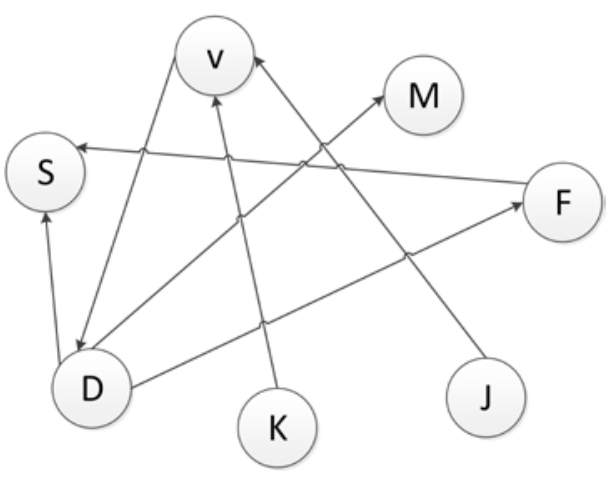

Fig. 4. Fault directed graph of CNC machine tools

\subsection{Hierarchical division of CNC machine tools subsystem}

The subsystem failure analysis is conducted, the influence matrix $\mathbf{Y}$ is directly affected, and the comprehensive influence matrix $\mathbf{T}$ is determined using the DEMATEL method.

$$
\mathbf{Y}=\begin{array}{r}
D \\
V \\
J \\
F \\
K \\
K
\end{array}\left[\begin{array}{lllllll}
0 & 0 & 0 & 0 & 0 & 0 & 0 \\
0 & 0 & 1 & 0 & 0 & 0 & 0 \\
2 & 0 & 0 & 2 & 0 & 3 & 0 \\
0 & 0 & 0 & 0 & 0 & 0 & 0 \\
0 & 1 & 0 & 0 & 0 & 0 & 0 \\
2 & 0 & 0 & 0 & 0 & 0 & 0 \\
0 & 2 & 0 & 0 & 0 & 0 & 0
\end{array}\right]
$$


Table 1 CNC machine tools subsystem partition

\begin{tabular}{|ccc|c|}
\hline \hline Site code & system name & Contains components \\
\hline $\mathrm{S}$ & Active system & $\begin{array}{c}\text { Including power cutting head, power box, spindle assembly, tools clamping mechanism and its } \\
\text { main moving parts }\end{array}$ \\
Including power slide, rail, screw and so on
\end{tabular}

Table 2. Associated fault data of CNC machine tools

\begin{tabular}{cccc}
\hline \hline Cause of failure & Subsequent failure site & Cause of failure & Subsequent failure site \\
\hline Fixture & Active system & Cooling chip removal system & Electrical System \\
Hydraulic system & Active system & Feed system & Electrical System \\
Cooling chip removal system & Electrical System & Hydraulic system & Active system \\
Hydraulic system & Fixture & Hydraulic system & Fixture \\
Hydraulic system & Manipulator & Fixture & Active system \\
Hydraulic system & Manipulator & Electrical System & Hydraulic system \\
Hydraulic system & Fixture & & \\
\hline \hline
\end{tabular}

$S$
$V$
$V$$\left[\begin{array}{ccccccc}0 & 0 & 0 & 0 & 0 & 0 & 0 \\ 0.0583 & 0 & 0.1428 & 0.0408 & 0 & 0.0612 & 0 \\ 0.4082 & 0 & 0 & 0.2857 & 0 & 0.4286 & 0 \\ 0 & 0 & 0 & 0 & 0 & 0 & 0 \\ F & K \\ 0.0086 & 0.1428 & 0.0204 & 0.0058 & 0 & 0.0087 & 0 \\ 0.2857 & 0 & 0 & 0 & 0 & 0 & 0 \\ 0.0167 & 0.2857 & 0.0408 & 0.0117 & 0 & 0.0175 & 0\end{array}\right]$

By comparing the row and column sum of the subsystems in $\mathbf{T}$, the ranking of correlation is sorted into hydraulic system, jig, active system, electric system and cooling system. Thus, the system overall impact matrix is:

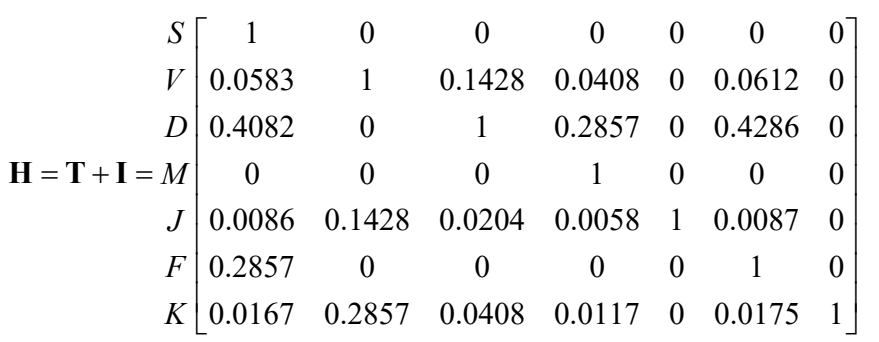

$$
m_{i j}=\left\{\begin{array}{l}
1 \mathrm{~h}_{\mathrm{ij}}>\lambda \\
0 \mathrm{~h}_{\mathrm{ij}} \leq \lambda
\end{array}(\mathrm{i}, \mathrm{j}=1, \cdots, \mathrm{n})\right. \text { to determine the element values in }
$$

the reachable matrix, which $\lambda$ is a given threshold for system simplification. For systems with a small value of $n$, set $\lambda=0$. Then, the reachable matrix $\mathbf{M}$ is:

$$
\mathbf{M}=M \quad \begin{aligned}
& S \\
& V \\
& J \\
& F
\end{aligned}\left[\begin{array}{lllllll}
1 & 0 & 0 & 0 & 0 & 0 & 0 \\
1 & 1 & 1 & 1 & 0 & 1 & 0 \\
1 & 0 & 1 & 1 & 0 & 1 & 0 \\
0 & 0 & 0 & 1 & 0 & 0 & 0 \\
1 & 1 & 1 & 1 & 1 & 1 & 0 \\
1 & 0 & 0 & 0 & 0 & 1 & 0 \\
1 & 1 & 1 & 1 & 0 & 1 & 1
\end{array}\right]
$$

The subsequent operation is simple, with $S_{1}$ on behalf of $S, S_{2}$ on behalf of $V, S_{3}$ on behalf of $D, S_{4}$ on behalf of $M, S_{5}$ on behalf of $J, S_{6}$ on behalf of $F$, and $S_{7}$ on behalf of $K$. Define the reachable set $R\left(S_{i}\right)$, antecedent set $A\left(S_{i}\right)$, common set $C\left(S_{i}\right)$, and initial set $B\left(S_{i}\right)$ of the factors, as shown in Table 3. 
Table 3. Reachable sets, Antecedent sets, Common sets, and Initial sets

\begin{tabular}{ccccc}
\hline \hline$S_{i}$ & $R\left(S_{i}\right)$ & $A\left(S_{i}\right)$ & $C\left(S_{i}\right)$ & $B\left(S_{i}\right)$ \\
\hline 1 & 1 & $1,2,3,5,6,7$ & 1 & \\
2 & $1,2,3,4,6$ & $2,5,7$ & 2 & \\
3 & $1,3,4,6$ & $2,3,5,7$ & 3 & \\
4 & 4 & $2,3,4,5,7$ & 4 & 5 \\
5 & $1,2,3,4,5,6$ & 5 & 5 & \\
6 & 1,6 & $2,3,5,6,7$ & 6 & 7 \\
7 & $1,2,3,4,6,7$ & 7 & 7 & \\
\hline \hline
\end{tabular}

Given that $B(S)=\left\{S_{5}, S_{7}\right\}$, and $R\left(S_{5}\right) \cap R\left(S_{7}\right) \neq \varnothing$, the system can only be divided into a region $P=\left\{S_{1}, S_{2}, S_{3}, S_{4}, S_{5}, S_{6}, S_{7}\right\}$. The same region $P$, in turn, is used to meet the elements of $R\left(S_{i}\right) \cap A\left(S_{i}\right)=R\left(S_{i}\right)$ to identify and define the highest levels of collection and the second level of the collection until the division is completed. See Table 4 for the details of the classification process.

Table 4. Level division process

\begin{tabular}{|c|c|c|c|c|c|c|}
\hline $\begin{array}{c}\text { Feature } \\
\text { set }\end{array}$ & $S_{i}$ & $R\left(S_{i}\right)$ & $A\left(S_{i}\right)$ & $R\left(S_{i}\right) \cap A\left(S_{i}\right)$ & $E(S)$ & $\prod(P)$ \\
\hline \multirow{7}{*}{$P-L_{0}$} & 1 & 1 & $1,2,3,5,6,7$ & 1 & & \multirow{7}{*}{$L_{1=}\left\{S_{1}, S_{4}\right\}$} \\
\hline & 2 & $1,2,3,4,6$ & $2,5,7$ & 2 & & \\
\hline & 3 & $1,3,4,6$ & $2,3,5,7$ & 3 & 1 & \\
\hline & 4 & 4 & $2,3,4,5,7$ & 4 & \multirow{4}{*}{4} & \\
\hline & 5 & $1,2,3,4,5,6$ & 5 & 5 & & \\
\hline & 6 & 1,6 & $2,3,5,6,7$ & 6 & & \\
\hline & 7 & $1,2,3,4,6,7$ & 7 & 7 & & \\
\hline \multirow{5}{*}{$P-L_{0}-L_{1}$} & 2 & $2,3,6$ & $2,5,7$ & 2 & & \multirow{5}{*}{$L_{2=}\left\{S_{6}\right\}$} \\
\hline & 3 & 3,6 & $2,3,5,7$ & 3 & & \\
\hline & 5 & $2,3,5,6$ & 5 & 5 & & \\
\hline & 6 & 6 & $2,3,5,6,7$ & 6 & & \\
\hline & 7 & $2,3,6,7$ & 7 & 7 & 6 & \\
\hline \multirow{4}{*}{$\begin{array}{c}P-L_{0}-L_{1} \\
-L_{2}\end{array}$} & 2 & 2,3 & $2,5,7$ & 2 & & \multirow{4}{*}{$L_{3=}\left\{S_{3}\right\}$} \\
\hline & 3 & 3 & $2,3,5,7$ & 3 & & \\
\hline & 5 & $2,3,5$ & 5 & 5 & 3 & \\
\hline & 7 & $2,3,7$ & 7 & 7 & & \\
\hline \multirow{3}{*}{$\begin{array}{c}P-L_{0}-L_{1} \\
-L_{2}-L_{3}\end{array}$} & 2 & 2 & $2,5,7$ & 2 & \multirow{3}{*}{2} & \multirow{3}{*}{$L_{4=}\left\{S_{2}\right\}$} \\
\hline & 5 & 2,5 & 5 & 5 & & \\
\hline & 7 & 2,7 & 7 & 7 & & \\
\hline \multirow{2}{*}{$\begin{array}{c}P-L_{0}-L_{1} \\
-L_{2}-L_{3}\end{array}$} & 5 & 5 & 5 & 5 & 5 & \multirow[b]{2}{*}{$L_{5}=\left\{S_{5}, S_{7}\right\}$} \\
\hline & 7 & 7 & 7 & 7 & 7 & \\
\hline
\end{tabular}

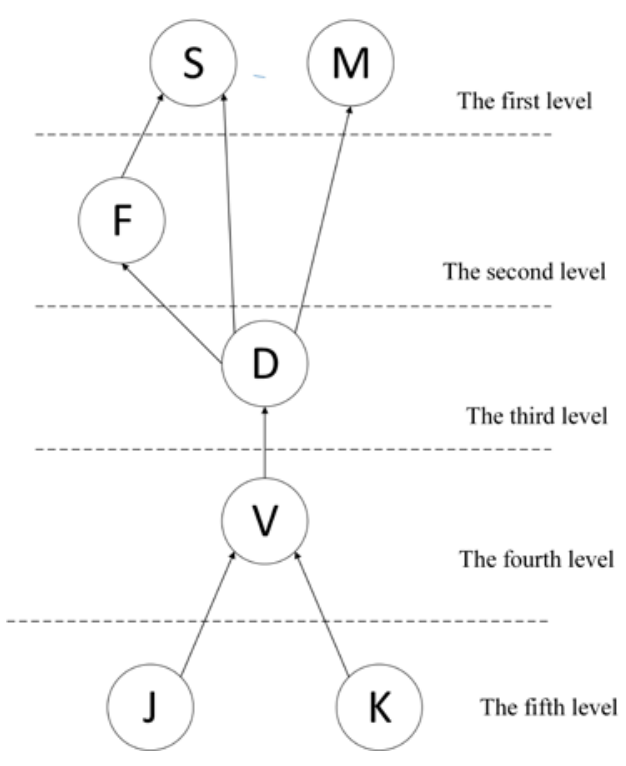

Fig. 5. Hierarchical structure model

$$
\mathbf{M}^{\prime}(\mathbf{L})=3\left[\begin{array}{lllllll}
1 & 3 \\
4 & 0 & 0 & 0 & 0 & 0 & 0 \\
0 & 1 & 0 & 0 & 0 & 0 & 0 \\
1 & 0 & 1 & 0 & 0 & 0 & 0 \\
1 & 1 & 1 & 1 & 0 & 0 & 0 \\
0 & 0 & 0 & 1 & 1 & 0 & 0 \\
0 & 0 & 0 & 0 & 1 & 1 & 0 \\
0 & 0 & 0 & 0 & 1 & 0 & 1
\end{array}\right]
$$

Further remove the unit matrix of $\mathbf{M}^{\prime}(\mathrm{L})$, and obtain the skeleton matrixwith binary relations:

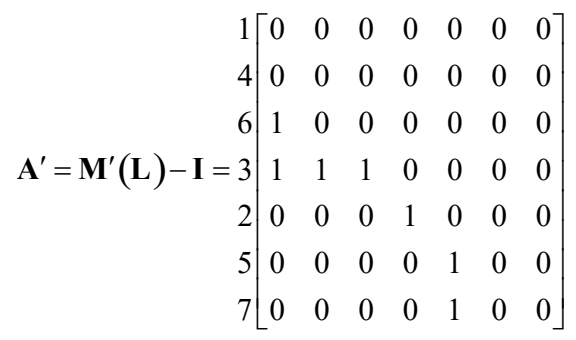

A hierarchical structure of system elements model can be

Termination set $E(S)$ in table 4 represent output elements show that the system can be divided into five levels: $L_{1=}\left\{S_{1}, S_{4}\right\}, L_{2}=\left\{S_{6}\right\}$, $L_{3=}=\left\{S_{3}\right\}, L_{4=}\left\{S_{2}\right\}$, and $L_{5=}\left\{S_{5}, S_{7}\right\}$. Determine the reachable matrix $\mathbf{M}(\mathrm{L})$ and remove the leapfrog binary relations among the elements to obtain $\mathbf{M}(\mathrm{L})$ :

$$
=\frac{1}{4}=3\left[\begin{array}{lllllll}
1 & 0 & 0 & 0 & 0 & 0 & 0 \\
0 & 1 & 0 & 0 & 0 & 0 & 0 \\
1 & 0 & 1 & 0 & 0 & 0 & 0 \\
1 & 1 & 1 & 1 & 0 & 0 & 0 \\
1 & 1 & 1 & 1 & 1 & 0 & 0 \\
1 & 1 & 1 & 1 & 1 & 1 & 0 \\
1 & 1 & 1 & 1 & 1 & 0 & 1
\end{array}\right]
$$
established, as shown in Fig. 5.

The model is a five-level hierarchical structure. The fifth-level elements influence the fourth level, the third level, the second level, the first level, and the final effect on machine reliability through a hierarchical relationship. The division of each subsystem level based

\begin{tabular}{|c|c|}
\hline System level & Contains subsystems \\
\hline Fault source subsystem & Feed system, cooling chip removal system \\
\hline $\begin{array}{l}\text { Intermediate fault sub- } \\
\text { system }\end{array}$ & $\begin{array}{c}\text { Fixtures, hydraulic systems, electrical } \\
\text { systems }\end{array}$ \\
\hline $\begin{array}{c}\text { Representation Subsys- } \\
\text { tem }\end{array}$ & Active system, manipulator \\
\hline
\end{tabular}
on the abovementioned analysis is shown in Table 5.

Table 5. Subsystems division 


\subsection{CNC machine tools subsystem failure rate modeling}

The data in this paper comprise a group of users in CNC machine tools, the collection and accumulation of five $\mathrm{CNC}$ machine tools, the on-site operation of the failure of data 28 , and the censored time data 5 , with a tracking cycle of six months. Fault data belongs to the fault source subsystem analysis, as presented in Table 6.

The absence of a "+" in the table represents the failure source data. The iterative calculation and failure of the source subsystem parameters while running the MATLAB program to conduct 100 iterations are also shown. The estimated values of the parameters are:

$$
\hat{\alpha}=367.4772, \hat{\beta}=1.4973
$$

Similarly, the parameters of the remaining subsystems as well as the deviation correction can be estimated. The results are shown in Table 7.

Table 7. Modified parameter values of subsystem reliability model

\begin{tabular}{|c|c|c|}
\hline Hierarchical subsystem & $\beta^{*}$ & $\alpha^{*}$ \\
\hline Fault source subsystem & 1.1492 & 370.8794 \\
\hline Intermediate fault subsystem & 0.9585 & 353.1728 \\
\hline Representation Subsystem & 0.7771 & 449.5970 \\
\hline
\end{tabular}

The failure time distribution function of $\mathrm{CNC}$ machine tools is tested by $d$, the observed value is $D_{n}=0.4078$. Take the significant level $\alpha=0.10$, check list $D_{n, \alpha}=1.22 / \sqrt{6}=0.498$. Since $D_{n}<D_{n, \alpha}$, the original hypothesis is accepted. The model passes the goodnessof-fit test, and the $\mathrm{CNC}$ machine tools fault time follows the Weibull distribution.

Therefore, the type of CNC machine tools fault source subsystem failure time function $\lambda_{1}(t)$ :

$$
\lambda_{1}(t)=\frac{1.1492}{370.8794}\left(\frac{t}{370.8794}\right)^{0.1492}
$$

Likewise, the failure rate function of the intermediate failure subsystem can be obtained:

$$
\lambda_{2}(t)=\frac{0.9585}{353.1728}\left(\frac{t}{353.1728}\right)^{-0.0415}
$$

Failure rate function of representation subsystem:

$$
\lambda_{3}(t)=\frac{0.7771}{449.5970}\left(\frac{t}{449.5970}\right)^{-0.2229}
$$

Based on the characteristics of the Gumbel-copula function, combined with the fault data of the intermediate sub- system and the failure source subsystem, using MATLAB software programming, and called the maximum likelihood estimation to obtain $\theta_{1}=0.254$. Similarly, the failure correlation coefficient of the representation subsystem with other two subsystems can be calculated as $\theta_{2}=0.198$.

At this point, considering the fault transfer and correlation, the overall reliability function:

$$
\begin{aligned}
& \left.R_{123}(t)=\exp \left\{-\left[\left[\left[\left(\frac{t}{370.8794}\right)^{1.1492}\right]^{1 / \theta_{1}}+\left[\left(\frac{t}{353.1728}\right)^{1.1492}\right]^{1 / \theta_{1}}\right]^{\theta_{1}}\right]^{1 / \theta_{2}}+\left[\left(\frac{t}{449.5970}\right)^{0.7771}\right]^{1 / \theta_{2}}\right]^{\theta_{2}}\right] \\
& =\exp \left\{\left[\left[\left(\frac{t}{370.8794}\right)^{4.5244}+\left(\frac{t}{353.1728}\right)^{3.7736}\right]^{1.2828}+\left(\frac{t}{449.5970}\right)^{2.349}\right]^{0.1980}\right\}
\end{aligned}
$$

Therefore, the integrated failure rate of each subsystem is:

$$
\begin{aligned}
& \lambda_{F}(t)=\lambda_{1}(t)=\frac{1.1492}{370.8794}\left(\frac{t}{370.8794}\right)^{0.1492} \\
& \lambda_{I}(t)=\lambda_{2}(t)+\left(1-\theta_{1}\right) \lambda_{1}(t)=\frac{0.9585}{353.1728}\left(\frac{t}{353.1728}\right)^{-0.0415}+\frac{0.8573}{370.8794}\left(\frac{t}{370.8794}\right)^{0.1492} \\
& \lambda_{R}(t)=\lambda_{3}(t)+\left(1-\theta_{2}\right) \lambda_{12}(t)=\frac{0.7771}{449.5970}\left(\frac{t}{449.5970}\right)^{-0.2229}+0.802 \times\left(\frac{t^{4.5244}}{370.8794^{4.5244}}+\frac{t^{3.7736}}{353.1728^{3.7736}}\right)^{-0.749} \\
& \times\left(\frac{1.1492 t^{3.5244}}{370.8794^{4.5244}}+\frac{0.9585 t^{2.7736}}{353.1728^{3.7736}}\right)
\end{aligned}
$$

\subsection{CNC machine tools subsystem maintenance time mod- eling}

The fault repair time information analysis and the finishing of CNC modular machine tools are shown in Table 8.

In the table, , ${ }^{*}$ " represents the fault source subsystem maintenance time data, "\#" represents the representation fault subsystem maintenance time data and the rest for the intermediate fault subsystem maintenance time data.

An example of the fault source subsystem to repair time processing is shown in Table 9.

Table 9. Fault source subsystem maintenance time processing

\begin{tabular}{ccccccc}
\hline \hline$i$ & $\tau_{i}$ & $X_{i}$ & $\bar{X}$ & $\sqrt{\frac{n}{n+1}} \cdot \frac{X_{i}-\bar{X}}{S}$ & $t_{n-1}\left(\sqrt{\frac{n}{n+1}} \cdot \frac{X_{i}-\bar{X}}{S}\right)$ & $\hat{p}_{i}$ \\
\hline 1 & 0.79 & -0.2357 & & -1.4609 & 0.1019 \\
2 & 2.00 & 0.6931 & & -0.6334 & 0.2772 \\
3 & 3.98 & 1.3813 & 1.0393 & -0.0204 & 0.4922 \\
4 & 6.62 & 1.8901 & & 0.4328 & 0.6584 \\
5 & 7.71 & 2.0425 & & 0.5686 & 0.7029 \\
6 & 14.21 & 2.6539 & & 1.1133 & 0.8419
\end{tabular}

Table 8. CNC machine tools failure repair time

\begin{tabular}{ccccccc}
\hline \hline Numbering & & & Maintenance time $\tau / \mathrm{h}$ & \\
\hline 1 & $10.62 \#$ & 3.00 & $0.79^{*}$ & $1.37 \#$ & 6.00 & 2.50 \\
2 & $8.00 \#$ & $16.69 \#$ & $2.00^{*}$ & $6.00 \#$ & & \\
3 & $3.98^{*}$ & $7.71^{*}$ & 2.20 & 6.30 & $6.62^{*}$ & $11.00 \#$ \\
4 & $14.21^{*}$ & 2.50 & $2.00 \#$ & $0.13 \#$ & 3.00 & \\
5 & 10.00 & 1.58 & 8.81 & $5.00 \#$ & 3.00 & 2.60 \\
\hline \hline
\end{tabular}


Table 10. Test results

\begin{tabular}{ccc}
\hline \hline Hierarchical subsystem & $M(t)=\int_{0}^{t} \frac{1}{\sigma x \sqrt{2 \pi}} \exp \left\{-\frac{1}{2}\left(\frac{\ln x-\mu}{\sigma}\right)^{2}\right\} d x$ & $m(t)=\frac{1}{\sigma t \sqrt{2 \pi}} \exp \left\{-\frac{1}{2}\left(\frac{\ln t-\mu}{\sigma}\right)^{2}\right\}$ \\
\hline Fault source subsystem & $\int_{0}^{t} \frac{1}{0.9488 x \sqrt{2 \pi}} \exp \left\{-\frac{1}{2}\left(\frac{\ln x-1.4042}{0.9488}\right)^{2}\right\} d x$ & $\frac{1}{0.9488 t \sqrt{2 \pi}} \exp \left\{-\frac{1}{2}\left(\frac{\ln t-1.4042}{0.9488}\right)^{2}\right\}$ \\
Intermediate fault subsystem & $\int_{0}^{t} \frac{1}{0.5259 x \sqrt{2 \pi}} \exp \left\{-\frac{1}{2}\left(\frac{\ln x-1.4609}{0.5259}\right)^{2}\right\} d x$ & $\frac{1}{0.5259 t \sqrt{2 \pi}} \exp \left\{-\frac{1}{2}\left(\frac{\ln t-1.4609}{0.5259}\right)^{2}\right\}$ \\
Representation Subsystem & $\int_{0}^{t} \frac{1}{1.1165 x \sqrt{2 \pi}} \exp \left\{-\frac{1}{2}\left(\frac{\ln x-1.336}{1.1165}\right)^{2}\right\} d x$ & $\frac{1}{1.1165 t \sqrt{2 \pi}} \exp \left\{-\frac{1}{2}\left(\frac{\ln t-1.336}{1.1165}\right)^{2}\right\}$ \\
\hline \hline
\end{tabular}

Table 11. Subsystem maintenance time distribution function

\begin{tabular}{ccc}
\hline \hline Hierarchical subsystem & $M(t)=\int_{0}^{t} \frac{1}{\sigma x \sqrt{2 \pi}} \exp \left\{-\frac{1}{2}\left(\frac{\ln x-\mu}{\sigma}\right)^{2}\right\} d x$ & $m(t)=\frac{1}{\sigma t \sqrt{2} \pi} \exp \left\{-\frac{1}{2}\left(\frac{\ln t-\mu}{\sigma}\right)^{2}\right\}$ \\
\hline Fault source subsystem & $\int_{0}^{t} \frac{1}{0.9488 x \sqrt{2 \pi}} \exp \left\{-\frac{1}{2}\left(\frac{\ln x-1.4042}{0.9488}\right)^{2}\right\} d x$ & $\frac{1}{0.9488 t \sqrt{2 \pi}} \exp \left\{-\frac{1}{2}\left(\frac{\ln t-1.4042}{0.9488}\right)^{2}\right\}$ \\
Intermediate fault subsystem & $\int_{0}^{t} \frac{1}{0.5259 x \sqrt{2 \pi}} \exp \left\{-\frac{1}{2}\left(\frac{\ln x-1.4609}{0.5259}\right)^{2}\right\} d x$ & $\frac{1}{0.5259 t \sqrt{2 \pi}} \exp \left\{-\frac{1}{2}\left(\frac{\ln t-1.4609}{0.5259}\right)^{2}\right\}$ \\
Representation Subsystem & $\int_{0}^{t} \frac{1}{1.1165 x \sqrt{2 \pi}} \exp \left\{-\frac{1}{2}\left(\frac{\ln x-1.3360}{1.1165}\right)^{2}\right\} d x$ & $\frac{1}{1.1165 t \sqrt{2 \pi}} \exp \left\{-\frac{1}{2}\left(\frac{\ln t-1.3360}{1.1165}\right)^{2}\right\}$ \\
\hline \hline
\end{tabular}

After using the PSO algorithm and programming with MATLAB, the parameter estimation values of the maintenance model of the fault source subsystem can be obtained $\hat{\mu}_{1}=1.4042, \hat{\sigma}_{1}=0.9488$. Similarly, the parameters of intermediate failure subsystems are estimated to be $\hat{\mu}_{2}=1.3553, \hat{\sigma}_{2}=0.5912$, and the parameters of representation failure subsystems are estimated to be $\hat{\mu}_{3}=1.3360, \hat{\sigma}_{3}=1.1165$.

The $d$ test was carried out to test the goodness-offit test, and the results are shown in Table 10 (using a significant level $\alpha=0.10$ ).

All $D_{n}<D_{n, \alpha}$, the maintenance time distribution function of each level subsystems was shown in Table 11 .

Using $M T T R=\int_{0}^{\infty} t m(t) d t=\exp \left(\mu+\frac{\sigma^{2}}{2}\right)$, the estimated values of MTTR of each subsystem are obtained, as shown in Table 12.

\section{Table 12. MTTR point estimates for subsystems}

\begin{tabular}{cc}
\hline \hline Hierarchical subsystem & MTTR (unit: $\mathrm{h}$ ) \\
\hline Fault source subsystem & 6.387 \\
Intermediate fault subsystem & 4.618 \\
Representation Subsystem & 7.094 \\
\hline \hline
\end{tabular}

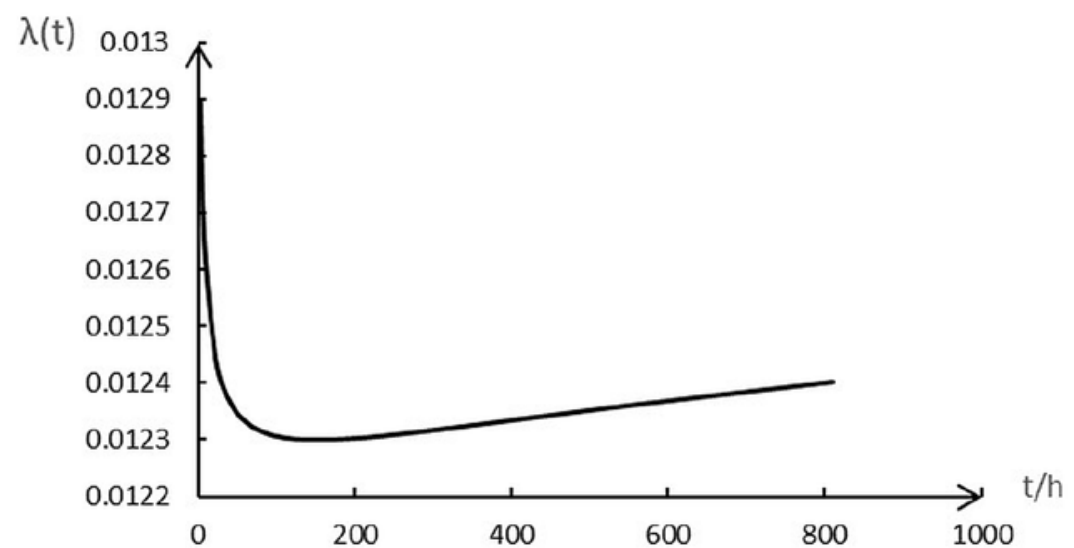

Fig. 6. Failure rate curve of CNC machine tools 


\subsection{Determination of average maintenance time of CNC machine tools}

1) Based on the series relation and the subsystem comprehensive failure rate function, the failure rate curve of $\mathrm{CNC}$ machine tools system as shown in Fig. 6.

Figure 6 shows that the minimum fault rate of this type of $\mathrm{CNC}$ machine tools is $\lambda_{\min }=0.0123$, corresponding to the fault time $t=100$ $\mathrm{h}$, and corresponding failure rate of the subsystems are as follows:

$$
\begin{aligned}
& \lambda_{F}(t)=\lambda_{F}(100)=0.00255 \\
& \lambda_{I}(t)=\lambda_{I}(100)=0.00476 \\
& \lambda_{R}(t)=\lambda_{R}(100)=0.00499
\end{aligned}
$$

The machine tools maintenance time is determined as follows:

$$
\begin{aligned}
& \operatorname{MTTR}_{(t=100)}=\frac{\sum \lambda_{i} M_{T T R}}{\sum \lambda_{i}} \\
& =\frac{\lambda_{F}(100) \bullet M T T R_{1}+\lambda_{I}(100) \bullet M T T R_{2}+\lambda_{R}(100) \bullet M T T R_{3}}{\lambda_{F}(100)+\lambda_{I}(100)+\lambda_{R}(100)}=5.99 \mathrm{~h}
\end{aligned}
$$

Therefore, the average maintenance time of $\mathrm{CNC}$ machine tools with the minimum failure rate is $5.99 \mathrm{~h}$.

2) Experience has shown that the maintenance time data mostly follow the lognormal distribution. The maintenance time in Table 8 is assumed to follow the lognormal distribution. Then, using the MLE method to estimate the parameters $\mu$ and $\sigma^{2}$, and the probability density function of maintenance time is obtained. Finally, the test results show that the maintenance time follows a lognormal distribution. Therefore, the probability density function and the average maintenance time for the whole machine can be obtained as:

$$
f_{l n}(t)=\frac{1}{1.01 \sqrt{2 \pi}} \exp \left[-\frac{1}{2}\left(\frac{\ln t-1.36}{1.01}\right)^{2}\right] \operatorname{MTTR}=\int_{0}^{\infty} \operatorname{tm}(t) d t=\exp \left(\mu+\frac{\sigma^{2}}{2}\right)=6.42 h
$$

\subsection{Comparative analysis}

Using the minimum failure rate and considering the number of subsystem failures and the corresponding average maintenance time, the subsystem maintenance time is obtained as

$$
R T_{i}=\operatorname{MTTR}_{i} \times \lambda_{i}(t) \times t_{\min }
$$

where $R T_{i}$ is the maintenance time of each subsystem; $i=1,2,3$ is the fault source subsystem, the intermediate fault subsystem, and the representation subsystem, respectively; and $t_{\min }=100 \mathrm{~h}$ is the minimum failure rate occurrence time.

The results are shown in Table 13.

Table 13. Subsystem maintenance time

\begin{tabular}{cc}
\hline \hline Hierarchical subsystem & $R T($ unit: $\mathrm{h})$ \\
\hline Fault source subsystem & 1.627 \\
Intermediate fault subsystem & 2.198 \\
Representation Subsystem & 3.539 \\
\hline \hline
\end{tabular}

$$
\begin{aligned}
& \text { Table } 13 \text { shows: } \quad R T_{R}>R T_{I}>R T_{F} \\
& \sum R T_{i}=\operatorname{MTTR}_{(t=100)} \times \lambda_{\text {min }} \times t_{\text {min }}
\end{aligned}
$$

where $\lambda_{\min }=0.0123$ is the minimum failure rate of time $t=100$. Formula (22) shows that the average maintenance time of the entire machine is equal to the sum of each subsystem repair time, which is in line with actual engineering practices; however, the traditional modeling method is required to determine the failure rate and the number of occurrences. The average maintenance time is not equal to the total maintenance time of all subsystems, which is contrary to actual applications.

2) The failure rate of the representation subsystem is the highest and its maintenance time is the longest because of the long fault location time. The fault source subsystem has the shortest maintenance time followed by the middle fault subsystem; the same applies for the total maintenance time. These results are consistent with the actual diagnosis and troubleshooting.

Therefore, the maintenance time requires a more reasonable design that considers the failure rate and fault frequency of the subsystem.

\section{Conclusion}

(1) (1) Considering the failure correlation, the DEMATEL-ISM method was introduced. DEMATEL method was used to construct the reachable matrix, and the ISM method is used to decompose the reachable matrix. The complexity of the system was transformed into a clear multi-level hierarchical structure model. Finally, the level of CNC machine tools in the subsystem division were determined.

(2) Using the time-dependent reliability model of each level as the edge distribution, the copula function was used to establish the system joint reliability distribution function to determine the correlation coefficient of each subsystem.

(3) The failure rate function model of each subsystem is established based on the failure rate correlation. Moreover, the average maintenance time model of the $\mathrm{CNC}$ machine tools was established under the minimum failure rate of the system.

(4) The average maintenance time of the whole system was determined while considering the number of failures and average maintenance time of each subsystem. Comparative analysis between the traditional maintenance modeling method and the average maintenance time showed that the latter equal to the sum of the maintenance time of each subsystem. This result is consistent with actual applications. The research also provides a basis for the subsystem maintenance time design, and has obtained a more reasonable design scheme for the average maintenance time of CNC machine tools.

\section{Acknowledgment}

The research work was financially supported by the National Science and Technology Major Project of China (Project No.2015ZX04003002), Natural Science Foundation of Jilin Province (Project No. 20150101025JC and 20170101212JC).

\section{References}

1. Bu Yingyong, Zhang Huailiang. The preliminary attempt to develop preventive-predictive maintenance. Journal of Central South University 1995: 2(2):32-36, https://doi.org/10.1007/BF02652004.

2. Charles E. Ebeling. An Introduction to Reliability and Maintainability Engineering. Tsinghua University Press 2010; 1:157-158.

3. Cheng Xiao-min, Jia Ya-zhou, Shu Ze. Statistical research on maintenance time of CNC machine tools. Machine Tools \& Hydraulics 1992; 
02:83-85.

4. Ebeling C E. An introduction to reliability and maintainability engineering. McGraw-Hill Education, New York 2004.

5. Huang Xi-li, Han Xi-an. Method for fuzzy maintainability index demonstration in lognormal distribution. Journal of Systems Engineering and Electronics 2008; 30(2): 375-378.

6. Kai Zhang, Jinchun Song, Guangan Ren, Jia Shi. Particle swarm optimization algorithm with multi methods argument. AI Communications 2016; P: 1-15.

7. Lam Y. A geometric Process Maintenance Model with Preventive Repair.European Journal of Operational Research 2007; 182: 806-819, https://doi.org/10.1016/j.ejor.2006.08.054.

8. Liu Duan, Hu Jian Bo, Ge Xiao Kai, el at. Monte Carlo Simulation of Maintenance Time Based on System Maintenance Work Procedure. Fire Control \& Command Control 2014; 39 (7): 119-123.

9. Lu Zhong, Sun You Chao, Wu Hai Qiao. System Maintainability Modeling Method Based on Colored Stochastic Time Petri Net. Journal of Mechanical Engineering 2011; 47 (10): 185-191, https://doi.org/10.3901/JME.2011.10.185.

10. Ma Zhan-Fei. ISM-based architecture for network security system. ICEIT 2010 -2010 International Conference on Educational and Information Technology Proceedings 2010:1969-2014.

11. Murthy D N P, Nguyen D G. Study of a multi-component system with failure interaction. Eu J Oper Res 1985; 21: 330-338, https://doi. org/10.1016/0377-2217(85)90153-5.

12. Radiša Djurić, Vladimir Milisavljević. Investigation of the relationship between reliability of track mechanism and mineral dust content in rocks of lignite open pits. Eksploatacja i Niezawodnosc - Maintenance and Reliability 2016; 18 (1): 142-150, https://doi.org/10.17531/ ein.2016.1.19.

13. Shahannaghi K, Babaei H, Bakhsha A et al. A New Condition Based Maintenance Model with Random Improvements on the System After Maintenance Actions:Optimizing by Monte Carlo Simulation].World Journal of Modeling and Simulation 2008; 4(3): $230-236$.

14. Shey-Huei Sheuab, Chin-Chih Changc, Yen-Luan Chend, Zhe George Zhangef. Optimal preventive maintenance and repair policies for multi-state systems. Reliability Engineering and System Safety 2015; 140: 78-87, https://doi.org/10.1016/j.ress.2015.03.029.

15. Sklar A. Fonctions de repartition an dimensions et leurs marges. Paris: Publication Institute Statist University 1959; 8: 229-231.

16. Sun Y, Ma L, Mathew J, et al. An analytical model for interactive failure. Reliability Engineering\& System Safety 2006; 91(5): 495-504, https://doi.org/10.1016/j.ress.2005.03.014.

17. U.S. Department of Defense. MIL-STD-470B Maintainability program requirements for systems and equipment. Ohio: Aeronautical system Center 1989.

18. Wang H Z, Pham H. Reliability and Optimal Maintenance. Springer-Verlag London: Springer Series in Reliability Engineering Series, 2006.

19. Wang L, Hu H J, Wang Y Q, et al. The Availability Model and Parameters Estimation Method for the Delay Time Model with Imperfect Maintenance at Inspection. Applied Mathematical Modeling 2011; (35): 2855-2863, https://doi.org/10.1016/j.apm.2010.11.070.

20. Wu Jingmin, Zuo Hongfu, Chen Yong. An estimation method for direct maintenance cost of aircraft components based on particle swarm optimization with immunity algorithm. Journal of Central South University 2005; 12(2): 95-101, https://doi.org/10.1007/s11771-0050018-9.

21. Wu W W. Choosing knowledge management strategies by using a combined ANP and DEMATEL approach. Expert Systems and Applications 2008; 35(3): 828-835, https://doi.org/10.1016/j.eswa.2007.07.025.

22. $\mathrm{Wu} \mathrm{Xi}, \mathrm{Xu} \mathrm{Da}, \mathrm{Mu} \mathrm{Ge}$, Li Chuang. Research on verification method of equipment maintenance time based on digital prototyping. Manufacturing Technology \& Machine Tool 2013; 12: 63-66.

23. Y. G. Petalas; K. E. Parsopoulos; M. N. Vrahatis. Memetic particle swarm optimization. Annals of Operations Research 2007; 155(1): 99127, https://doi.org/10.1007/s10479-007-0224-y.

24. Zhang Deng-Feng, Fei Sheng-Wei, Liu Yuan-Wei, Sun Yu. Approach on failure diagnosis knowledge acquisition in beginning stage of maintenance for complex equipments. Journal of Central South University (Science and Technology) 2009; 40(S1): 284-289.

25. Zhang Hai-bo, Liu Liang, Huang Yang-yang. Maintain Time Model of CNC Machining Center. Modular Machine Tools \& Automatic Manufacturing Technique 2014; 05:158-160.

26. Zhuoqi Zhang, Su Wu, Binfeng Li. Opportunistic maintenance policy for a two-unit system with failure interactions. Journal of Tsinghua University(Science and Technology) 2012; 52(1):122-127.

27. Zuo F-J, Yu L, Mi J, Liu Z, Huang H-Z. Reliability analysis of gear transmission with considering failure correlation. Eksploatacja i Niezawodnosc - Maintenance and Reliability 2015; 17 (4): 617-623, https://doi.org/10.17531/ein.2015.4.19.

\section{Guixiang SHEN \\ Wenbin ZENG \\ Chenyu HAN}

NC equipment credibility Engineering Research

Institute

College of Mechanical Science and Engineering

Jilin University

People str., 5988 Changchun, 130022, China

\section{Peng LIU \\ Yingzhi ZHANG}

Department of Industrial Engineering
College of Mechanical Science and Engineering
Jilin University
People str., 5988 Changchun, Jilin 130022, China

Emails:313442341@qq.com, zengwb15@yeah.net, 1094267138@qq.com,969929715@qq.com, 569679064@qq.com 